\title{
PERSPECTIVES OF FUTURE TEACHERS OF EARLY YEARS FROM TWO PORTUGUESE INSTITUTIONS ON THE HISTORY OF MATHEMATICS
}

\author{
C. Costa ${ }^{1}$, L. Menezes ${ }^{2}$, A. Ribeiro ${ }^{2}$, H. Pinto ${ }^{3}$, A.P. Martins ${ }^{4}$, T. Costa Clain ${ }^{5}$, \\ H. Gomes ${ }^{6}$, A.P. Aires ${ }^{1}$ \\ ${ }^{1}$ Universidade de Trás-os-Montes e Alto Douro and CIDTFF (PORTUGAL) \\ ${ }^{2}$ Instituto Politécnico de Viseu, Escola Superior de Educação and CI\&DETS (PORTUGAL) \\ ${ }^{3}$ Piaget Institute, RECI and CIDMA (PORTUGAL) \\ ${ }^{4}$ Instituto Politécnico de Viseu, Escola Superior de Educação and CIUHCT (PORTUGAL) \\ ${ }^{5}$ Escola Secundária D. Maria II and CIDMA (PORTUGAL) \\ ${ }^{6}$ Instituto Politécnico de Viseu, Escola Superior de Educação and CIDMA (PORTUGAL)
}

\begin{abstract}
Several studies point out that History of Mathematics (HM) can have a relevant role in mathematics teaching and learning. Still, in Portugal its use in non-higher education is very limited, which brings challenges to trainers of future teachers (FT). It seemed important to us to find out how the FT: (i) characterise their training in $\mathrm{HM}$, obtained in their first cycle academic degree; (ii) evaluate the impact that the use of HM had on their learning of mathematical topics; and (iii) appreciate the didactic potential of using HM in mathematics classes. To this goal, we design a mixed study with FT graduating at two Portuguese institutions. Data were collected from questionnaires $(\mathrm{N}=28)$ and semi-structured interview $(\mathrm{N}=2)$. Data analysis combines qualitative and quantitative aspects. It reveals that, $\mathrm{FT}$ of both institutions had contact with HM mainly in the introduction to contents and mentions to the history of symbology, they also show having more memories of HM in course units that HM as a focus of study. In terms of the impact of $\mathrm{HM}$ on their learning of mathematics, the FT highlight that it facilitated the understanding of mathematical content and connections between mathematics and reality, promoting also the development of transversal skills. In terms of appreciation of the didactic potentialities of using HM in teaching, the FT highlight that it allows illustrating relationships of Mathematics with other subjects. The interviewed FT also revealed difficulty to present/explain the didactic potential of HM, which may occur because in this initial degree they still have little contact with teaching practices and also because HM is used as a tool and less as a didactic approach that they may use in the professional master's degree.
\end{abstract}

Keywords: Teacher education, History of Mathematics, Perspectives and experiences of future teachers.

\section{INTRODUCTION}

The History of Mathematics (HM) has been identified as a resource with high didactic potential ([1], [2], [3], [4]). Among these potentialities, we highlight the following: (i) It allows Mathematics to be seen as a cultural product, unfinished resulting from human effort, in which doubt and error are present; (ii) Allows to illustrate relationships between different mathematical domains and with other sciences; (iii) Enables the development of transversal skills beyond mathematical knowledge; and (iv) Encourage students' motivation to learn Mathematics. Despite this, the classroom practices of using HM are scarce ([1], [2], [3], [5], [6]), a fact that poses challenges and responsibilities to teacher education. In particular, also, in Portugal, the use of $\mathrm{HM}$ in non-higher education is not very frequent. This fact poses challenges to the training of future teachers (FT) in HM. Teachers in Portugal, who teach mathematics up to the $6^{\text {th }}$ grade of schooling, have a compulsory 3-year degree (Basic Education (BE) degree), followed by a professional master's degree.

As teacher trainers, we consider it pertinent to know what goes on in initial teacher education, particularly in the first years of schooling (K1 to K6). In this context, this study aims to find out how the FT of these levels' students: (i) characterise their training in HM, obtained in their academic degree in BE; (ii) evaluate the impact that the use of HM had on their learning of mathematical topics; and (iii) appreciate the didactic potential of using HM in mathematics classes.

To this goal, we designed a research study with a mixed methodology. We focus our study in two Portuguese higher education institutions (named School A and School B). 
In the next section we provide a brief theoretical background on the use of HM in mathematics teaching, followed by section 3 on the methodological aspects of the study. Section 4 is devoted to the presentation of the results. The first subsection presents the results related to training in HM in each of the institutions analysed, the second subsection presents the perspectives of future teachers of early years of the same institutions and the third one presents the perspectives on HM of two future teachers (named Maria and Rosana). We finish with study main conclusions.

\section{HISTORY OF MATHEMATICS IN MATHEMATICS TEACHING}

The importance of $\mathrm{HM}$ and its potential for mathematics teaching has been the subject of study by several authors over time ([1], [2], [4], [7], [8], [9], [10], [11], [12], [13]). As early as 1969 Jones argued that HM should be taught so that

"students understand the "whys," teaching for meaning and understanding, teaching so that children see and appreciate the nature, role, and fascination of mathematics, teaching so that students know that men are still creating mathematics and that they too may have the thrill of discovery and invention" ([7], p.1).

And in a logic of the "whys" of teaching mathematics, Jones ([7]) presents HM as a powerful didactic tool that the teacher has at his disposal and allows him to respond, skilfully and effectively to the three "whys" of his teaching: Chronological "whys" that enable a sequential understanding of the contents and consequently an interaction between new and previous knowledge; Logical "whys" that allow students to learn a more complex content from its origin, which leads them to develop their perceptions or logical conceptions; Pedagogical "whys" that allows the teacher, through access to past situations, to organize a good pedagogical sequence concerning a specific content and thus facilitate its teaching and understanding by the students. These concerns about the teaching of mathematics and HM, as a didactic resource for the teacher, have received increasing attention over time. Specifically, the contribution of HM to answer the pedagogical "whys" is particularly important because it challenges us, as teachers, to think about teaching practices that promote an effective and meaningful learning of mathematics. Thus, the question arises: How can we integrate HM into these teaching practices? We highlight some examples that the teacher can use and consequent possible benefits. I) Introduction of biographies relating to mathematicians who, in some way, contributed to the creation or development of a concept or theory that the students are learning: it allows, first of all, to present mathematicians as human beings like us who just lived in another time and who worked in the service of an idea, for years, often without success and deserved recognition ([14]). In this context the student may see mathematics as a human construction and feel more motivated to learn this science. II) Presentation of historical narratives, sometimes even anecdotal episodes of mathematicians, to introduce new concepts: it allows you to know how concepts in mathematics originated and developed, and to illustrate the teaching of some mathematical concepts with some anecdotes that show that mathematicians are ordinary people [15]. III) Presenting historical problems to which the concepts the students are learning provide the answer: this approach allows students to recognize that mathematics is a science in the making and to understand its evolutionary nature where concepts are refined over time. IV) Explore misunderstandings/errors/alternative views of the past: these explorations allow the teacher to develop mechanisms to understand his students' errors and, at the same time, to appropriate knowledge that will enable him to plan didactic situations that anticipate and prevent them from occurring. Moreover, the teacher can, based on the mistakes of great mathematicians, make students aware that mistakes are an integral part of the construction of knowledge, and are a way to help them improve and progress in their learning. From the students' point of view, when they see that the great "geniuses" of mathematics experienced difficulties and often made mistakes, it may lead to the emergence of a feeling of "comfort" in relation to the subject, since they are not the only ones to make mistakes and experience difficulties, which will promote the development of positive attitudes towards the subject ([9]). The integration of HM brings benefits not only for the students, but also for the teacher. It can be a challenge to their knowledge by presenting them with new information and procedures, and to their creativity by providing material that will lead them to think about new ways of planning their lessons. As a result, the teacher enriches his or her knowledge on the one hand, and his or her didactic repertoire on the other, by exploring new explanations, examples, and new approaches to teaching.

Obviously, if the teacher has a natural predisposition and taste for $\mathrm{HM}$ and is able to transmit this taste to his/her students, involving them in the preparation and presentation of historical themes of mathematics in his/her classes, thus introducing them to research, this is done almost in a natural way. However, as teacher trainers, we believe that it is possible and essential to promote this attitude and taste in future teachers. This study points in that direction. 


\section{METHODOLOGY}

Considering the objectives of the study and, naturally, the nature of the collected data, we adopted a mixed methodology, combining a quantitative and a qualitative approach [16]. Participants are FP (all female, with an average age of 22 years old) graduating from $B E$ at two teacher training Portuguese institutions (to maintain anonymity, designated as "school A" and "school B") that make use of HM. FP were asked by: (i) online questionnaire with a four-level agreement scale, 4 being the maximum level of agreement) ( $\mathrm{N}=28$ ); and (ii) semi-structured interview (we interviewed two TF, one from each school, Maria and Rosana (pseudonyms)). The questions asked in the questionnaire are presented below, in the study results. In order to be able to cross-check information, BE future teachers were asked a questionnaire about whether or not they used HM in their classes and if so, asked for some of the material they used. Data analysis combines qualitative and quantitative techniques such as statistical analysis and content analysis. Data analysis uses descriptive statistical analysis techniques. The coefficient of variation (CV) was used to evaluate the representativity of the mean-value (the meanvalue will be the more representative the lower the $\mathrm{CV}$ value; for $\mathrm{CV}>50 \%$ the mean-value is not considered representative) [17]. In data analysis, we only highlight the items where the mean-value is most significant.

\section{RESULTS}

The results are organized into three sections: (1) History of Mathematics in two Portuguese institutions; (2) Perspectives of future teachers of early years from two Portuguese institutions on the History of Mathematics; and (3) Perspectives of future teachers on the History of Mathematics: Two cases.

\subsection{History of Mathematics in two Portuguese institutions}

In this section, we describe the training in the $\mathrm{HM}$ given in the $\mathrm{BE}$ in two Portuguese higher education institutions (School A and School B). For this, we invite BE Mathematics and Didactics of Mathematics teachers to describe this training, providing examples of approaches, illustrations and tasks on HM.

\subsubsection{Training in History of Mathematics at School A}

Training in HM takes place in two ways: (i) Training in HM; and (ii) Mathematics training supported by HM. Training in HM occurs in a curricular unit that addresses questions about the evolution of mathematical knowledge (Early manifestations of Mathematics; Mathematics in the main civilizations of Antiquity; Emergence of the main domains of Mathematics: from Antiquity to the present) with questions about the nature of this knowledge and also cultural issues (approach to Ethnomathematics). This curricular unit $(\mathrm{CU})$ combines elements of a theoretical nature regarding the emergence and evolution of mathematical concepts and their forms of representation (using primary sources, theoretical texts and videos) with the resolution of historically framed problems, such as about the comparison of the system of Babylonian numeration with the decimal, the unit fractions of the Egyptians, the figured numbers of the Pythagoreans). An example of a task on figured numbers (reported to Ancient Greece) is presented in Figure1.

In the others Mathematics CUs of the BE Degree, HM is used as a teaching methodology, making the historical framing of several concepts and the resolution of mathematical tasks framed historically. At the CU Algebra, in the topic "Relations and regularities", the following work is proposed: "Analysis of regularities in the Fibonacci succession; Fibonacci rabbits' task; Analysis of regularities in fractals; Sierpinski triangle task; Sum of the first $n$ terms of an arithmetic progression (exploration of Gauss' approach)". To introduce Coordinate Geometry, the need for object orientation is discussed, as well as the creation of references over time. The study starts with the orientation by stars, so important in the past navigation of Portuguese sailors, for example, and then other references, until reaching the GPS and references studied in school mathematics. For this study, articles and videos are used. In other CUs, such as Numbers and Operations, and Statistics and Probabilities, episodic historical references are made regarding the evolution of this mathematical knowledge. 


\section{Numbers in Ancient Greece}

1. The arrangement of points representing numbers in triangular, square, pentagonal, etc. schemes it will have taken into account the succession of triangular numbers, square numbers, pentagonal numbers, etc.

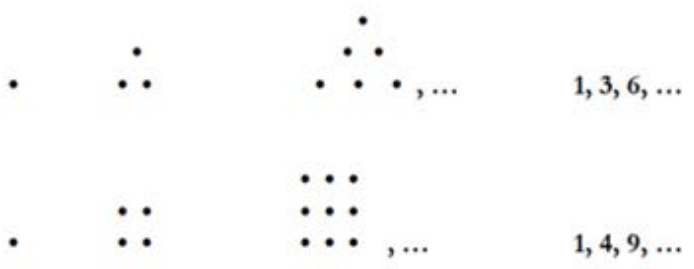

1.1 Determine the first ten terms of the triangular numbers succession $\left(t_{n}\right)$ and of the square numbers succession $\left(q_{n}\right)$.

1.2 Write the general expressions of the two successions, $\left(t_{n}\right)$ and $\left(q_{n}\right)$.

1.3 Investigate the relationship between square numbers and triangular numbers.

2.The search for rectangular schemes to represent numbers will have led to the concept of divisibility.

2.1 What kinds of rectangular representations support prime numbers? What about composite numbers?

2.2 For each of the representations of the rectangular numbers, what does the number of rows and columns represent?

2.3 Investigate other relationships of rectangular numbers.

Figure 1. Task on Figured Numbers (Ancient Greece).

\subsubsection{Training in History of Mathematics at School B}

Training in HM takes place in two ways: (i) Training in HM; and (ii) Mathematics training supported by HM. It occurs only in two curricular units: Science History and Numbers and Operations. The first one addresses questions about the evolution of science and meet the following challenges: (i) Need for training on the processes of construction of scientific knowledge held by teaching modules that present a dynamic view of science and of recent developments and issues that present themselves to society; (ii) Using the History of Science in order to improve science learning and scientific culture of students. Some topics focus HM, specifically about the contributions of relevant mathematicians, using theoretical texts, questionnaires, tasks and videos (e.g. film Agora and others where references to mathematicians appear).

In the other Mathematics CU of the BE Degree, Numbers and Operations, HM is used as a teaching methodology, making the historical framing of several concepts and the resolution of mathematical tasks framed historically. This can be seen in the topic "The origin and evolution of numbers. Definition of natural number; The Babylonian, Mayan, Egyptian, Roman and Hindu-Arabic numbers". The notion of natural number is given as well as an historical perspective of the evolution of numeration systems, towards a better comprehension of them. As an example, we present, in Figure 2, two additions in the numeration system used in old Egypt [18]. 


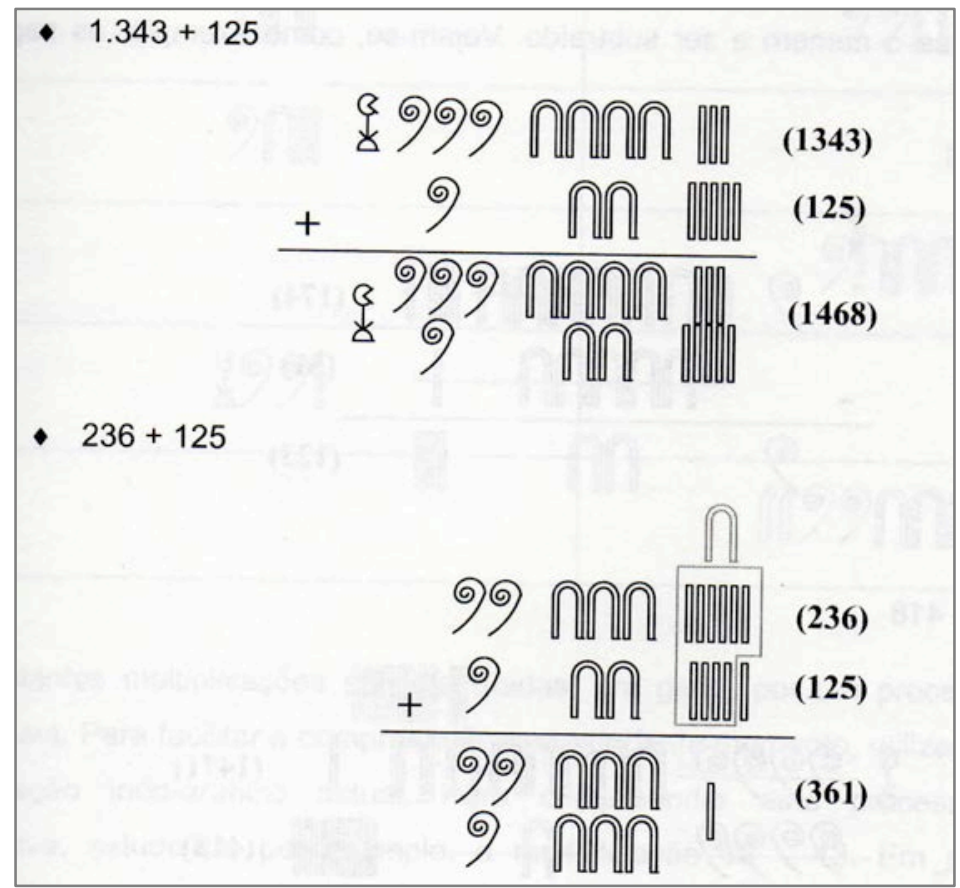

Figure 2. Examples of additions in the Egyptian numeration system ([18], p. 11).

\subsection{Perspectives of future teachers of early years from two Portuguese institutions on the History of Mathematics}

Most FT $(57,5 \%)$, on average, with higher value in School A $(75 \%)$ than in School B $(37,5 \%)$, characterize their training in $\mathrm{HM}$, in $\mathrm{BE}$, as "Frequent". We emphasize that, on average, $16.25 \%$ of the participants (similar values in the two schools) consider their training in HM "Solid (for example, taking a course in the area of HM)". These values contrast with the values related to previous education (until $\mathrm{K} 12$ ) when $67,5 \%$ of the FT consider their training in HM as "non-existent" or "reduced".

FT were asked how HM was introduced in their math classes. Table 1 presents these results:

Table 1. Initial training in HM.

\begin{tabular}{|c|c|c|c|}
\hline Item & School & Average & CV (\%) \\
\hline \multirow{2}{*}{ In the introduction to mathematical content. } & $A$ & 3,25 & 13 \\
\hline & $B$ & 2,75 & 35 \\
\hline \multirow{2}{*}{ In the introduction to the history of mathematical symbology. } & $A$ & 3,05 & 19 \\
\hline & $B$ & 2,50 & 34 \\
\hline \multirow{2}{*}{ In the development of mathematical content. } & $A$ & 3,10 & 17 \\
\hline & $B$ & 2,87 & 36 \\
\hline \multirow{2}{*}{ In solving mathematical tasks. } & $A$ & 2,95 & 22 \\
\hline & $B$ & 2,12 & 49 \\
\hline \multirow{2}{*}{ In extra-class research/projects. } & $A$ & 3,15 & 15 \\
\hline & $B$ & 2,25 & 43 \\
\hline
\end{tabular}

The results reveal higher levels of agreement of the FT from school A, with the majority of averages above 3. Teachers highlighted the following ways of using Mathematics in class: "In the introduction to mathematical content" (mean score of 3,25 ), "In extra-class research/projects" (mean score of 3,15 ) and "In the development of mathematical content" (mean score of 3,10).

From the HM resources used in the classes, the following stand out: "Primary sources" (mean score of 3,00 ), "Texts/videos/websites with narratives/interpretations/historical reconstructions" (mean score of 
3,00 ) and "Teaching material related to the HM" (mean score of 3,00 ). In general, in this question the levels of agreement are lower than the previous question (Table 2).

Table 2. Experiences using HM to learn.

\begin{tabular}{l|c|c|c}
\hline \multicolumn{1}{c|}{ Item } & School & Average & CV (\%) \\
\hline \multirow{2}{*}{ Primary sources (excerpts from original mathematical documents). } & $A$ & 3,00 & 14 \\
\cline { 2 - 4 } & $B$ & 2,37 & 51 \\
\hline Texts/videos/websites with narratives/interpretations/historical & $A$ & 3,00 & 18 \\
reconstructions. & $B$ & 2,12 & 49 \\
\hline \multirow{2}{*}{ Teaching material related to the History of Mathematics. } & $A$ & 3,00 & 14 \\
\hline \multirow{2}{*}{ Teaching material related to the History of Mathematics elaborated by me. } & $B$ & 1,75 & 47 \\
\hline \multirow{2}{*}{ Mathematicians' biographies. } & $A$ & 2,40 & 35 \\
\hline \multirow{2}{*}{ Problems with historical context. } & $B$ & 1,75 & 47 \\
\hline \multirow{2}{*}{ Ancient games. } & $B$ & 2,05 & 47 \\
\hline \multirow{2}{*}{ Ancient instruments (mechanical/mathematical). } & $A$ & 2,70 & 23 \\
\cline { 2 - 4 } & $B$ & 2,00 & 52 \\
\hline \hline
\end{tabular}

Invited to describe one of these HM practices in Mathematics class, no FT responded.

Table 3 shows the answer to the question: "How do you assess the impact that the use of the History of Mathematics had on your learning?"

Table 3. Impact that the use of the History of Mathematics had on learning.

\begin{tabular}{|c|c|c|c|}
\hline Item & School & Average & $C V(\%)$ \\
\hline \multirow{2}{*}{ It facilitated the understanding of mathematical content. } & $A$ & 3,20 & 15 \\
\hline & $B$ & 2,62 & 42 \\
\hline \multirow{2}{*}{$\begin{array}{l}\text { I developed transversal skills such as mathematical communication, } \\
\text { problem solving and mathematical reasoning. }\end{array}$} & $A$ & 3,00 & 14 \\
\hline & $B$ & 2,50 & 40 \\
\hline \multirow{2}{*}{ My motivation for solving the proposed tasks increased. } & $A$ & 2,75 & 22 \\
\hline & $B$ & 2,5 & 40 \\
\hline \multirow{2}{*}{$\begin{array}{l}\text { I managed to establish more easily connections between Mathematics } \\
\text { and reality. }\end{array}$} & $A$ & 3,00 & 14 \\
\hline & $B$ & 2,50 & 40 \\
\hline \multirow{2}{*}{$\begin{array}{l}\text { I managed to establish more easily links between Mathematics and } \\
\text { other areas of knowledge. }\end{array}$} & $A$ & 2,80 & 21 \\
\hline & $B$ & 2,12 & 43 \\
\hline \multirow{2}{*}{ It allowed me to enjoy Mathematics more. } & $A$ & 2,70 & 26 \\
\hline & $B$ & 2,12 & 49 \\
\hline
\end{tabular}

FT from school A stand out from the rest, revealing higher levels of agreement in the following statements: "It facilitated the understanding of mathematical content" (mean score of 3,20), "I developed transversal skills such as mathematical" $(3,00)$ and "I managed to establish more easily connections between" (mean score of 3,00).

Table 4 presents the results to the question: "Appreciate the potential of using the History of Mathematics in Mathematics class.". 
Table 4. Conceptions about the use of HM to teach.

\begin{tabular}{|c|c|c|c|}
\hline Item & Scholl & Average & $C V(\%)$ \\
\hline \multirow{2}{*}{$\begin{array}{l}\text { It favours the demystification of mathematics as a finished product, showing } \\
\text { that doubt and error are part of human (mathematical) activity. }\end{array}$} & $A$ & 2,90 & 21 \\
\hline & $B$ & 2,50 & 44 \\
\hline \multirow{2}{*}{ Allows to illustrate the utility and importance of Mathematics. } & $A$ & 3,10 & 17 \\
\hline & $B$ & 2,63 & 42 \\
\hline \multirow{2}{*}{ Allows to illustrate relationships between different mathematical domains. } & $A$ & 3,00 & 10 \\
\hline & $B$ & 2,63 & 42 \\
\hline \multirow{2}{*}{$\begin{array}{l}\text { Allows you to illustrate relationships between mathematics and other } \\
\text { disciplines. }\end{array}$} & $A$ & 3,10 & 14 \\
\hline & $B$ & 2,50 & 40 \\
\hline \multirow{2}{*}{ Allows a different approach to mathematics than usual. } & $A$ & 3,20 & 12 \\
\hline & $B$ & 2,63 & 42 \\
\hline \multirow{2}{*}{$\begin{array}{l}\text { It enables the development of skills beyond mathematical knowledge, such as } \\
\text { documenting, analyzing and discussing mathematical subjects. }\end{array}$} & $A$ & 3,00 & 10 \\
\hline & $B$ & 2,38 & 41 \\
\hline \multirow{2}{*}{ It encourages students to be motivated to learn Mathematics. } & $A$ & 3,00 & 23 \\
\hline & $B$ & 2,50 & 40 \\
\hline
\end{tabular}

The FT, especially those from school A, underline the potential of using the HM in Mathematics class (average agreement levels around 3), with the following statements being highlighted: "Allows a different approach to mathematics than usual." (mean score of 3,20 ) and "Allows you to illustrate relationships between mathematics and other disciplines" (mean score of 3,10 ).

\subsection{Perspectives of future teachers on the History of Mathematics: Two cases}

In this section, we present the perspectives of two future teachers on the HM, The cases of Maria and Rosana.

\subsubsection{The case of Maria (School A)}

Maria was 22 years old at the time of completion of the BE Degree, during which showed great involvement and enjoyment with the prospect of becoming a teacher in the early years. Regarding the use of $\mathrm{HM}$ in Mathematics/Didactics of Mathematics classes during the BE, Maria essentially remembers a $\mathrm{CU}$ in which HM was an explicit teaching topic: "I remember that in Foundations of Mathematics we spoke at HM, in the origins when it was a practical activity, for example, for inheritances and land divisions, in Egypt, and later in Ancient Greece, when it was already an activity to think about". Maria recalls in this CU the use of videos, texts and tasks with ancient problems and recognizes the underlying objective of this work: "As we have to teach Mathematics, it is not enough to know Mathematics, it is necessary to know the origins of Mathematics". Maria reveals difficulty in identifying HM in the other Mathematics CUs of BE, referring to two other CUs: "I vaguely remember that we also spoke in Geometry (...) and in Probability and Statistics, I remember saying that Statistics is more recent, it's different (...) that it wasn't always part of Mathematics because it uses different methods". For this reason, Maria is unable to appreciate the impact that the use of HM in Mathematics/Didactics classes had on her learning of mathematical concepts.

In terms of the appreciation of HM's pedagogical potential in teaching, although without having had the opportunity to experience it in practice, she considers that it could contribute to motivate students: "With $\mathrm{HM}$, students can gain more motivation to understand Mathematics, to see how Mathematics came about (...) Mathematics has always existed, this is an established point, and it is important for students to understand if it has always existed in this way". Furthermore, Maria believes that HM can lead students to look at mistakes in a more positive way: "We should demystify mistakes, students have to realize that they learn from mistakes (...) we can make mistakes many times, but every time we have to learn something". Maria concludes that the BE should give more emphasis to HM; "I think that in BE we should have more training in the HM, as happens in Portuguese, in which we study the origin of words". 


\subsubsection{The case of Rosana (School B)}

Rosana was also 22 years old at the time of completion of the BE Degree, during which showed great involvement and enjoyment with the prospect of becoming a teacher in the early years. Regarding the use of HM in Mathematics/Didactics of Mathematics classes during the BE, Rosana vaguely remembers them talking about HM in Didactics of Mathematics classes. Rosana reveals difficulty in identifying HM in other Mathematics CUs of BE mentioning that "In the other CUs I don't think I heard about it, because they were more practical". When asked by the interviewer about the possible use of HM in the CU of Numbers and Operations, Rosana recalled that: "The only thing that was talked about was when we were introduced to Egyptian and Roman numerals, but that was the only aspect, nothing else, that I can remember". Rosana recalls that in this subject the teacher used a presentation program and that she provided them a sheet with the different numbering systems, what the symbols used in each one, and what number they corresponded to. Rosana spontaneously mentioned that her overall assessment of the reference to HM in the BE was that "it was little talked about, I even think it should be talked about more so that we can understand how it came about".

In terms of the appreciation of HM's pedagogical potential in teaching, although without having had the opportunity to experience it in practice, Rosana believes that HM has potential both for teacher training ("to understand where the content that we were taught came from and why it was necessary that it was created") and for teacher practice ("we can then teach it better in our role as a teacher"). In addition, she considers that it can work as motivation for the students: "To understand what came first and how it evolved to where we are today, also to captivate the children so that they become more interested and more committed, trying to overcome their difficulties themselves". Furthermore, Rosana believes that HM can lead students to look at mathematics and their own difficulties in a more positive way: "Maybe even giving us more comfort. If in the past there were also setbacks and advances before you got to the point you've reached. If I'm wrong, that won't mean that I won't be able to overcome my difficulties."

\section{CONCLUSIONS}

This study found that the use of HM in teacher training in the BE degree differs depending on the training institution. In the two cases studied, School A uses HM more frequently, in an integrated and more diversified way in most CUs, while in School B its use is occasional (in two CUs) and very reduced. The modes of use of $\mathrm{HM}$ are those known from the literature, especially, the exposition of topics, the reference to HM mathematicians, the use of videos or films, and the performance of tasks on HM or with HM support. When invited to give examples of uses of HM in their education, the FT, especially the interviewees, reveal some difficulties in presenting them. Notice also that FT show having more memories of HM in course units that had HM as a focus of study, more than when HM was used to introduce/develop mathematical topics. In terms of the impact of HM on their learning of mathematics, the FT highlight, "It facilitated the understanding of mathematical content", "I was able to make connections between mathematics and reality more easily", "I developed transversal skills". In terms of appreciation of the didactic potentialities of using HM in teaching, the FT highlight, "It allows illustrating relationships of Mathematics with other subjects". However, the two interviewed FT also revealed do not easily recognize that they have been subjected to learning with or about $\mathrm{HM}$, associating $\mathrm{HM}$ with the idea of theoretical content. Still, they are able to recognize advantages in the use of HM in their training in $\mathrm{BE}$, both for a better and deeper understanding of the contents that are part of their curriculum, but also to know how to teach them better in their future professional practice. It should also be noted that both mentioned that HM has the potential to improve students' conceptions of mathematics and, mainly, to give them "comfort" in their learning and in overcoming the difficulties that this learning brings.

\section{ACKNOWLEDGEMENTS}

This work is funded by National Funds through the FCT - Foundation for Science and Technology. We would like to thank: Centre for Studies in Education and Innovation (CI\&DEI), Research in Education and Community Intervention (RECl), Center for Research \& Development in Mathematics and Applications (CIDMA, references UIDB/04106/2020 and UIDP/04106/2020), Centro Interuniversitário de História das Ciências e da Tecnologia (CIUHCT) and Research Centre on Didactics and Technology in the Education of Trainers (CIDTFF). 


\section{REFERENCES}

[1] K. Clark, T. Kjeldsen, S. Schorcht, \& C. Tzanakis (eds.), Mathematics, Education and History: Towards a Harmonious Partnership (ICME-13). Cham, Germany:Springer, 2018.

[2] K. Clark, "History and Pedagogy of mathematics in mathematics education: History of the field, the potencial of current exemples, and directions for the future", in U. T. Jankvist, M. Heuvel-Panhuizen, \& M. Veldhuis (Eds.), Eleventh Congress of the European Society for Research in Mathematics Education, pp. 29-55, Utrecht University and ERME, 2019.

[3] V. Katz, The History of Mathematics. An Introduction ( $3^{\text {rd }}$ edition). Boston: Pearson Education Inc., 2009.

[4] H. Pinto, H., \& C. Costa, "La Historia de las Matemáticas en los Cursos de Educación Básica en Portugal: una Reflexión para la Formación del Profesorado", Paradigma - Revista Del Centro de Investigaciones Educacionales, vol.41, no. 1, pp1-19, 2020. https://doi.org/10.37618/PARADIGMA.1011-2251.2020.p01-19.id830

[5] I. Gonçalves (2011). Os problemas da matemática: o seu papel na matemática e nas aulas de matemática. (Tese de doutoramento não editada, Matemática - Ensino da Matemática). Universidade da Madeira, Portugal, 2011.

[6] HPM. (2021). History and Pedagogy of Mathematics Group, 2021. http://www.clab.edc.uoc.gr/HPM/about HPM.htm,I

[7] P. S. Jones, "The history of mathematics as a teaching tool", in NCTM (Ed.), Historical topics for the mathematics classroom, pp. 1-17. Washinton, D. C: NCTM, 1969.

[8] D. J. Struik, História Concisa da Matemática (2.a Ed.). Lisboa: Gradiva, 1992.

[9] J. Fauvel, "A utilização da História em Educação Matemática", in A. Vieira, E. Veloso \& M. J. Lagarto. (Eds.), Relevância da História no Ensino da matemática, Cadernos do GTHEM no. 1, pp. 15-20. Lisboa: GTHEM/APM, 1997.

[10] J. Fauvel, \& J. van Maanen (Eds.), History in mathematics education-The ICMI study. Dordrecht: Kluwer, 2000.

[11] M. N. Fried, "Can mathematics education and history of mathematics coexist?", Science \& Education, vol.10, pp.391- 408, 2001.

[12] U. D’Ambrósio, Educação Matemática: da teoria à prática, 23 ed. Campinas: Papirus, 2012.

[13] T. Kjeldsen, \& M. Blomhøj, "Beyond motivation: history as a method for learning meta-discursive rules in mathematics", Educ Stud Math, vol. 80, pp. 327-349, 2012.

[14] M. F. Estrada, "A História da Matemática no ensino da Matemática", Educação e Matemática, vol.27, pp.17-21, 1993.

[15] M. E. Ralha, Didáctica da Matemática: Perspectivas gerais sobre educação matemática. Lisboa: Universidade Aberta,1992.

[16] T. Duarte. A possibilidade da investigação a 3: reflexões sobre triangulação (metodológica). Lisboa: CIES-ISCTE, 2009.

[17] A. Afonso, \& C. Nunes. Estatística e Probabilidades. Aplicações e Soluções em SPSS. Escolar Editora, 2010.

[18] H. Pinto, História da Matemática na Sala de Aula (2. ${ }^{a}$ ed.). Lisboa: Associação Ludus, 2011. 